\title{
HUBUNGAN KEBUTUHAN AFILIASI DENGAN PERILAKU PROSOSIAL PADA REMAJA
}

\author{
Fadhila Maharani \\ Program Studi Psikologi, Fakultas IImu Pendidikan, Universitas Negeri Padang, e-mail: \\ raniadhila@gmail.com
}

\section{ABSTRACT: RELATIONSHIP OF NEED OF AFFILIATION WITH PROSOCIAL BEHAVIOR IN ADOLESCENTS}

Prosocial behavior is an act that is given sincerely to help someone. This present study examines the relationship between affiliation needs and prosocial behavior in adolescents. This research uses quantitative methods with a correlational design. Accidental sampling technique was used for sampling. The participants in this study were 100 adolescents aged 12-22 years in Pekanbaru, Riau. The scale of affiliation needs adapted from Minanti (2017) and prosocial behavior adapted from Anzala (2018) were used as data collection methods. The data analysis in this study used Pearson product moment correlation and was assisted by the SPSS 16.0 for windows program. The results showed that there is a significant positive relationship between the need for affiliation and prosocial behavior in adolescents in Pekanbaru City. Thus, it can be concluded that the need for affiliation associated with prosocial behavior.

\section{Keywords: Need of Affiliation, Prosocial Behavior, Adolescents}

Perilaku prososial ialah tindakan yang diberikan secara tulus untuk membantu seseorang. Penelitian ini bertujuan untuk mengetahui hubungan antara kebutuhan afiliasi dengan perilaku prososial pada remaja. Penelitian ini menggunakan metode kuantitatif dengan desain korelasional. Teknik accidental sampling digunakan untuk pengambilan sampel. Partisipan dalam penelitian ini berjumlah 100 remaja berusia 12-22 tahun yang berada di Kota Pekanbaru, Riau. Skala kebutuhan afiliasi yang diadaptasi dari Minanti (2017) dan perilaku prososial yang diadaptasi dari Anzala (2018) digunakan sebagai metode pengumpulan data. Analisis data dalam penelitian ini menggunakan korelasi Pearson product moment dan dibantu oleh program SPSS 16.0 for windows. Hasil penelitian menunjukkan terdapat hubungan positif yang signifikan antara kebutuhan afiliasi dan perilaku prososial pada remaja di Kota Pekanbaru. Dengan demikian, dapat ditarik kesimpulan bahwa kebutuhan afiliasi berkaitan dengan perilaku prososial. Hasil penelitian menunjukkan terdapat hubungan positif yang signifikan antara kebutuhan afiliasi dan perilaku prososial pada remaja di Kota Pekanbaru. Dengan demikian, dapat ditarik kesimpulan bahwa kebutuhan afiliasi berkaitan dengan perilaku prososial.

\section{Kata Kunci: Kebutuhan Afiliasi, Perilaku Prososial, Remaja}

\section{PENDAHULUAN}

Individu merupakan makhluk sosial.

Oleh karena itu, individu harus berinteraksi dengan orang lain dan akan memerlukan bantuan orang lain dalam menjalani kehidupannya. Namun, hakikat individu sebagai makhluk sosial mulai luntur seiring berkembangnya zaman (Farida, 2017).
Masa remaja dianggap menjadi masa yang paling penting dalam mengajarkan individu untuk bersosialisasi karena pada masa ini terjadi perubahan yang dapat mengembangkan remaja menuju masa dewasa yang lebih sehat (Wahyuni, 2018; Zarkasih Putro, 2017). Remaja juga dituntut untuk dapat memenuhi tugas perkembangannya, salah satunya yaitu dengan 


\section{HUBUNGAN KEBUTUHAN AFILIASI DENGAN PERILAKU PROSOSIAL PADA REMAJA}

menjadi pribadi yang bertanggung jawab dan dapat diterima secara sosial (Manning, 2002).

Dalam interaksi sosial, perilaku yang kerap muncul yaitu perilaku prososial. Perilaku prososial didefinisikan sebagai perbuatan tulus untuk membantu seseorang sehingga penerima bantuan akan mendapatkan manfaat dan keuntungan (Heinla, Heijkoop, Houwing, Olivier, \& Snoeren, 2020; Yu, Li, \& Zhao, 2020). Eisenberg dan Mussen (dalam Devi, Yusuf, \& Hardjono, 2017) menyatakan perilaku prososial sebagai tindakan yang didasarkan pada empati dan kepedulian sehingga dapat memberikan faedah bagi orang lain.

Berdasarkan pengambilan data awal bersama tiga orang remaja yang bersekolah di SMA yang berbeda, mengungkapkan bahwa terdapat beberapa kasus kekerasan baik secara verbal maupun fisik yang terjadi di sekolah mereka. Remaja pertama mengatakan bahwa di sekolahnya pernah terjadi kasus dimana teman yang tidak sekelas dengannya mendapatkan tindakan kekerasan secara fisik dan verbal dengan dimaki serta dijambak oleh kakak kelasnya dan tidak ada yang berani menolongnya karena takut dengan kakak kelas tersebut. Permasalahan ini terjadi karena korban dianggap merebut pacar pelaku. Remaja kedua mengatakan bahwa ia pernah diejek dengan kata-kata gendut, jerawatan dan hitam. Sedangkan remaja ketiga mengatakan bahwa banyak temannya yang tidak menghargai guruseperti berbicara ketika guru sedang menerangkan pelajaran, melawan dan berkata tidak sopan.

Beberapa perilaku agresif diatas menunjukkan adanya sikap anti sosial yang dimiliki oleh para pelaku. Untuk mengurangi perilaku-perilaku tersebut dapat dilakukan dengan memiliki perilaku prososial, karena fungsi perilaku prososial yaitu sebagai cara untuk mendapatkan ikatan yang baik dalam interaksi dengan orang lain (Afrianti \& Anggraeni, 2016).

Remaja yang memiliki perilaku prososial akan membantu orang lain mengembangkan keterampilannya, membela, memuji dan memberikan semangat pada orang lain, memperkuat persahabatan, berkerja sama, serta dapat menghibur orang lain (Bashori, 2017; Bergin, Talley, \& Hamer, 2003).

Individu yang tidak dapat menunjukkan perilaku prososialnya akan berdampak pada sulitnya diterima di lingkungan sosial (Pitaloka \& Ediati, 2015). Sullivan (dalam Sari, Sakti, \& Fauziah, 2013) mengatakan bahwa jika remaja tidak diterima secara sosial, mereka akan kesepian, harga diri menjadi rendah, dan tak jarang sampai depresi.

Perilaku prososial pada individu dapat dipengaruhi oleh beberapa hal. Salah satunya yaitu agar dapat diterima secara sosial di lingkungan sekitarnya (Kau, 2010). Hal ini karena hakikat individu sebagai makhluk sosial

Fadhila Maharani, Program Studi Psikologi Fakultas Ilmu Pendidikan Universitas Negeri Padang. Email: raniadhila@gmail.com 


\section{HUBUNGAN KEBUTUHAN AFILIASI DENGAN PERILAKU PROSOSIAL PADA REMAJA}

mengakibatkan individu ingin menjalin hubungan dengan orang lain disekitarnya.

McClelland (dalam Rizky, Erlyani, \& Akbar, 2020) mengatakan kebutuhan afiliasi ialah keinginan untuk berhubungan dengan orang lain. Murray (dalam Puspita, Ifdil, \& Neviyarni, 2018) menambahkan dengan adanya kebutuhan afiliasi, individu akan berusaha menjaga hubungannya dengan orang lain. Sependapat dengan Murray, Baumeismer dan Leary (Marpaung, 2018) mengatakan bahwa kebutuhan afiliasi akan membuat individu mempertahankan hubungannya dengan orang lain agar dapat diterima di lingkungannya.

Penelitian menemukan bahwa dari 50 remaja, 23 orang menunjukkan kebutuhan afiliasi yang rendah (Rinjani \& Firmanto, 2013). Kemudian pada penelitian yang dilakukan oleh Putra dan Marheni (2015) ditemukan bahwa 47 remaja memiliki kebutuhan afiliasi yang rendah.

Remaja yang memiliki kebutuhan afiliasi yang rendah cenderung individualis, kurang mampu beradaptasi dengan lingkungan sosial, kurang termotivasi menyelesaikan pekerjaan sekolah, memiliki kepercayaan diri yang rendah dan kurang peduli dengan pendapat orang lain (Saputra, Tagela, \& Setyorini, 2019; Puspita, Ifdil, \& Neviyarni, 2018).

Telah banyak penelitian terdahulu yang meneliti mengenai perilaku prososial, namun masih sedikit yang meneliti hubungan kebutuhan afiliasi dan perilaku prososial dalam bidang pendidikan di Indonesia. Oleh karena itu, peneliti ingin meneliti tema tersebut untuk melihat hubungan antara kebutuhan afiliasi dengan perilaku prososial pada remaja.

\section{METODE}

Penelitian ini menggunakan metode kuantitatif dengan desain korelasional. Variabel yang digunakan adalah kebutuhan afiliasi sebagai variabel 1 dan perilaku prososial sebagai variabel 2.

Populasi dalam penelitian ini adalah remaja yang berada di Kota Pekanbaru, Riau. Teknik yang digunakan dalam pengambilan sampel adalah teknik accidental sampling dimana setiap individu yang ditemui dapat menjadi subjek penelitian. Sampel yang didapatkan yaitu berjumlah 100 orang remaja di Kota Pekanbaru berusia 12-22 tahun yang terdiri dari 15 laki-laki dan 85 perempuan dengan rata-rata usia 19.31 dan standar deviasi 1.98.

Teknik pengumpulan data menggunakan skala kebutuhan afiliasi dan perilaku prososial berbentuk skala likert. Skala kebutuhan afiliasi diadaptasi dari Minanti (2017) berdasarkan aspek yang disampaikan oleh MC Clelland yang mencakup 15 aitem. Indeks validitas pada skala kebutuhan afiliasi antara $.31-.81$ dan nilai reliabilitas sebesar .73 . Sedangkan skala perilaku prososial diadaptasi dari Anzala (2018) berdasarkan aspek yang dikemukakan oleh Mussen yang mencakup 31

Fadhila Maharani, Program Studi Psikologi Fakultas Ilmu Pendidikan Universitas Negeri Padang. Email: raniadhila@gmail.com 


\section{HUBUNGAN KEBUTUHAN AFILIASI DENGAN PERILAKU PROSOSIAL PADA REMAJA}

aitem. Indeks validitas pada skala perilaku

prososial antara .34 - .68 dan nilai reliabilitas

sebesar .92
Analisis dalam penelitian ini menggunakan teknik korelasi Pearson product moment dengan bantuan program SPSS 16.0 for windows

\section{HASIL}

Tabel 1

Kategorisasi Kebutuhan Afiliasi dan Perilaku Prososial

\begin{tabular}{ccccc}
\hline & \multicolumn{2}{c}{ Kebutuhan Afiliasi } & \multicolumn{2}{c}{ Perilaku Prososial } \\
\hline Kategori & $\mathrm{F}$ & $\%$ & $\mathrm{~F}$ & $\%$ \\
\hline Tinggi & 15 & 15 & 51 & 51 \\
\hline Sedang & 70 & 70 & 1 & 48 \\
\hline Rendah & 15 & 15 & 48 & 1 \\
\hline
\end{tabular}

Berdasarkan tabel 1, diketahui bahwa sebagian besar remaja memiliki kebutuhan afiliasi yang sedang $(70 \%)$ dan perilaku prososial yang tinggi (51\%). Lebih lanjut, sebelum menganalisis hubungan antar variabel penelitian, peneliti melakukan uji normalitas dan uji linieritas sebagai syarat uji korelasi. Berdasarkan uji normalitas, data ditemukan terdistribusi normal baik untuk kebutuhan afiliasi (K-SZ = 1.30, $p$ $>$.05) dan perilaku prososial $(\mathrm{K}-\mathrm{SZ}=.72, \mathrm{p}>05)$. Berdasarkan uji linearitas, ditemukan hubungan variabel 1 dan 2 linear $(p<.01)$

Berdasarkan uji hipotesis, ditemukan adanya hubungan positif signifikan antara kebutuhan afiliasi dengan perilaku prososial $(r(100)=.62, p<.01)$. Dengan demikian dapat dikatakan jika kebutuhan afiliasi tinggi maka perilaku prososial akan tinggi pula dan begitu sebaliknya.

\section{DISKUSI}

Hasil yang diperoleh dari uji hipotesis, terdapat hubungan antara variabel kebutuhan afiliasi dengan variabel perilaku prososial. Dengan demikian, hipotesis awal yang mengemukakan adanya hubungan antara kebutuhan afiliasi dan perilaku prososial pada remaja dapat diterima. Dengan diterimanya hipotesis penelitian, maka kebutuhan afiliasi dapat meningkatkan perilaku prososial. Hasil ini diperkuat oleh penelitian yang dilakukan oleh Chinopfukutwa dan Hektner, (2020) dimana kebutuhan afiliasi dapat memprediksi secara signifikan perilaku prososial.

Fadhila Maharani, Program Studi Psikologi Fakultas Ilmu Pendidikan Universitas Negeri Padang. Email: raniadhila@gmail.com 


\section{HUBUNGAN KEBUTUHAN AFILIASI DENGAN PERILAKU PROSOSIAL PADA REMAJA}

Perilaku prososial adalah tindakan perkembangan pada periode ini adalah untuk membantu orang lain dalam mencapai tujuan penerima bantuan tanpa mengharapkan imbalan atau keuntungan dari tindakan tersebut (Heinla, Heijkoop, \& Houwing, 2020; Yu, Li, \& Zhao, 2020).

Dari hasil penelitian, ditemukan bahwa tingkat prososial pada remaja berada di kategori yang tinggi. Remaja yang memiliki tingkat prososial yang tinggi lebih mudah beradaptasi di lingkungan baru, juga cenderung memiliki harga diri dan tanggung jawab yang tinggi (Noya, 2018; Sari, Sakti, \& Fauziah, 2013). Remaja yang memiliki perilaku prososial yang tinggi juga cenderung dapat diterima di lingkungannya (Pitaloka \& Ediati, 2015). Hal ini juga diperkuat oleh penelitian Zimmer-Gembeck, Geiger, dan Crick (2005) yang menemukan bahwa perilaku prososial dapat memprediksi hubungan dengan teman sebaya. Ketika remaja memiliki kebutuhan afiliasi maka remaja akan menunjukkan perilaku prososial sehingga mereka akan disukai oleh teman dan diterima di lingkungannya.

McClelland (Rizky, Erlyani, \& Akbar, 2020) mengatakan kebutuhan afiliasi didefinisikan sebagaidorongan untuk memiliki hubungan dengan orang lain. Dari hasil penelitian, didapatkan bahwa remaja memiliki tingkat kebutuhan afiliasi yang sedang.

Kebutuhan afiliasi sangat penting pada masa remaja karena salah satu tugas tercapainya hubungan yang matang dengan teman sebaya dan dapat diterima secara sosial (Ardi, Ibrahim, \& Said, 2012). Sullivan (Sari, Sakti, \& Fauziah, 2013)mengatakan bahwa jika remaja tidak diterima secara sosial, mereka akan kesepian, harga diri menjadi rendah, dan tak jarang sampai depresi. Oleh sebab itu, remaja dengan kebutuhan afiliasi yang tinggi akan cenderung terhindar dari beberapa masalah di atas karena mereka akan berupaya menjalin hubungan dengan orang lain dan lingkungan sekitar.

Adapun limitasi dari penelitian ini adalah pengambilan data yang menggunakan kuesioner yang disebarkan secara online yang dapat menurunkan kualitas informasi. Kemudian, jumlah subjek yang sedikit, kurang dapat mencerminkan keadaan yang sesungguhnya.

\section{SIMPULAN DAN SARAN}

Berdasarkan hasil dari analisis data dapat disimpulkan bahwa terdapat hubungan yang positif secara signifikan antara kebutuhan afiliasi dengan perilaku prososial pada remaja yang berada di Kota Pekanbaru, Riau. Dalam penelitian ini juga dapat disimpulkan bahwa dengan memiliki kebutuhan afiliasi dapat meningkatkan perilaku prososial pada remaja.

Berdasarkan temuan pada penelitian ini, peneliti memberikan beberapa saran kepada remaja untuk dapat mengembangkan ataupun

Fadhila Maharani, Program Studi Psikologi Fakultas Ilmu Pendidikan Universitas Negeri Padang. Email: raniadhila@gmail.com 


\section{HUBUNGAN KEBUTUHAN AFILIASI DENGAN PERILAKU PROSOSIAL PADA REMAJA}

mengungkapkan kebutuhan afiliasinya karena individu memerlukan orang lain dalam menjalani kehidupan serta dampak negatif yang dapat ditimbulkan dari perilaku prososial yang rendah dapat dihindari.

Bagi peneliti selanjutnya diharapkan dalam pengambilan data melalui kuesioner juga melakukan wawancara sebagai data pendukung dan memperbanyak jumlah subjek agar dapat mencerminkan keadaan yang sesungguhnya.

\section{DAFTAR PUSTAKA}

Afrianti, N., \& Anggraeni, D. (2016). Perilaku prososial remaja dalam perspektif bimbingan konseling islami. Ta'dib: Jurnal Pendidikan Islam, 5(1), 77-90.

Anzala, A. R. (2018). Hubungan Efikasi Diri dengan Perilaku Prososial pada Santri Mahasiswa di Pondok Pesantren $X$ Yogyakarta.

Ardi, Z., Ibrahim, Y., \& Said, A. (2012). Capaian tugas perkembangan sosial siswa dengan kelompok teman sebaya dan implikasinya terhadap program pelayanan bimbingan dan konseling. Konselor, 1(2).

Bashori, K. (2017). Menyemai perilaku prososial di sekolah. Sukma: Jurnal Pendidikan, 1(1), 57-92.

Bergin, C., Talley, S., \& Hamer, L. (2003). Prosocial behaviours of young adolescents: a focus group study. Journal of adolescence, 26(1), 13-32.

Chinopfukutwa, V. S., \& Hektner, J. M. (2020). Peer crowd affiliations as predictors of prosocial and risky behaviors among college students. Journal of American College Health, 1-10.

Devi, A. T., Yusuf, M., \& Hardjono, H. (2017). The relationship between sense of community and agreeableness with prosocial behavior among member of Young on Top (YOT). Journal of ICSAR, 1(1), 6-12.

Farida, H. (2017). Perilaku Prososial Ditinjau dari Androgyny Role dalam Kegiatan Pramuka Pada Anak Sekolah Dasar. SOSIOHUMANIORA: Jurnal IImiah IImu Sosial Dan Humaniora, 3(2).

Heinla, I., Heijkoop, R., Houwing, D. J., Olivier, J. D., \& Snoeren, E. M. (2020). Third-party prosocial behavior in adult female rats is impaired after perinatal fluoxetine exposure. Physiology \& behavior, 222, 112899.

Kau, M. A. (2010). Empati dan perilaku prososial pada anak. Jurnal Inovasi, 7(03).

Manning, M. L. (2002). Havighurst's developmental tasks, young adolescents, and diversity. The Clearing House, 76(2), 75-78.

Marpaung, W. (2018). AFFILIATION NEED VIEWED FROM LONELINESS ON STUDENTS LIVING AT DORMITORY OF UNIVERSITY OF SARI MUTIARA INDONESIA INDONESIA MEDAN. JURNAL PSYCHOMUTIARA, 1(1), 51-58.

Minanti, R. D. (2017). HUBUNGAN KEBUTUHAN AFILIASI DENGAN PENGUNGKAPAN DIRI PADA PENGGUNA MEDIA SOSIAL (Doctoral dissertation, University of Muhammadiyah Malang).

Fadhila Maharani, Program Studi Psikologi Fakultas Ilmu Pendidikan Universitas Negeri Padang. Email: raniadhila@gmail.com 


\section{HUBUNGAN KEBUTUHAN AFILIASI DENGAN PERILAKU PROSOSIAL PADA REMAJA}

Noya, M. D. A. (2018). HUBUNGAN ANTARA INTERNAL LOCUS OF CONTROL DENGAN PERILAKU PROSOSIAL PADA PELAJAR DI SMA NEGERI I HALMAHERA UTARA. Hibualamo: Seri IImu-IImu Sosial dan Kependidikan, 2(1), 10-17.

Pitaloka, D. A., \& Ediati, A. (2015). Rasa syukur dan kecenderungan perilaku prososial pada mahasiswa fakultas psikologi universitas diponegoro. Jurnal Empati, $4(2), 43-50$.

Putra, I. P. G. D., \& Marheni, A. (2015). Hubungan kebutuhan afiliasi dengan intensitas penggunaan jejaring sosial twitter pada remaja akhir. Jurnal Psikologi Udayana, 2(1).

Puspita, S., Ifdil, I., \& Neviyarni, S. (2018). Kebutuhan Afiliasi Siswa. Jurnal Konseling dan Pendidikan, 6(3), 191-197.

Rinjani, H., \& Firmanto, A. (2013). Kebutuhan afiliasi dengan intensitas mengakses facebook pada remaja. Jurnal IImiah Psikologi Terapan, 1(1), 76-85.

Rizky, L., Erlyani, N., \& Akbar, S. N. (2020). HUBUNGAN ANTARA KEBUTUHAN AFILIASI DENGAN PENGELOLAAN KESAN PADA REMAJA PENGGUNA MEDIA SOSIAL INSTAGRAM DI SMA NEGERI 2 BANJARBARU. Jurnal Kognisia: Jurnal Mahasiswa Psikologi Online, 1(1), 68-75.

Saputra, F. R., Tagela, U., \& Setyorini, S. HUBUNGAN ANTARA KOMUNIKASI INTERPERSONAL DENGAN KEBUTUHAN AFILIASI SISWA KELAS VIII SMP NEGERI 1 BANDUNGAN KABUPATEN SEMARANG TAHUN AJARAN 2018/2019. PSIKOLOGI KONSELING, 15(2).
Sari, N. H. P., Sakti, H., \& Fauziah, N. (2013). Motivasi berafiliasi dengan lawan jenis ditinjau dari persepsi remaja terhadap perceraian orang tua di Kecamatan Mijen. Empati, 2(4), 344-353.

Wahyuni, N. S. (2018). Hubungan Harga Diri dengan Perilaku Prososial pada Remaja Masjid di Kelurahan Denai.

Yu, G., Li, S., \& Zhao, F. (2020). Childhood maltreatment and prosocial behavior among Chinese adolescents: Roles of empathy and gratitude. Child abuse \& neglect, 101, 104319.

Zarkasih Putro, K. (2017). Memahami ciri dan tugas perkembangan masa remaja. Aplikasia: Jurnal Aplikasi IImu-IImu Agama, 17(1).

Zimmer-Gembeck, M. J., Geiger, T. C., \& Crick, N. R. (2005). Relational and physical aggression, prosocial behavior, and peer relations: Gender moderation and bidirectional associations. The Journal of Early Adolescence, 25(4), 421-452.

Fadhila Maharani, Program Studi Psikologi Fakultas Ilmu Pendidikan Universitas Negeri Padang. Email: raniadhila@gmail.com 